\title{
Comparative study on the epidemiological aspects of enterohemorrhagic Escherichia coli infections between Korea and Japan, 2006 to 2010
}

\author{
Won-Chang Lee ${ }^{1}$ and Young Hwan Kwon ${ }^{2}$
}

${ }^{1}$ College of Veterinary Medicine, Konkuk University, Seoul; ${ }^{2}$ Department of Internal Medicine, Aeromedical Center of Korean Air, Seoul, Korea

\footnotetext{
Received: August 21, 2014

Revised : March 25, 2015

Accepted: April 27, 2015

\section{Correspondence to}

Young Hwan Kwon, M.D.

Department of Internal Medicine, Aeromedical Center of Korean Air, 260 Haneul-gil, Gangseo-gu, Seoul 07505, Korea

Tel: +82-2-2656-7150

Fax: +82-2-2656-3839

E-mail: younghkwon@koreanair.com
}

Background/Aims: To compare the epidemiological aspects of enterohemorrhagic Escherichia coli (EHEC) between Korea and Japan by analyzing the current state of EHEC infection outbreaks and related risk factors.

Methods: We investigated the epidemiological aspects of EHEC infection cases between Korea and Japan from 2006 to 2010 . The following factors were analyzed: national prevalence rate (PR), regional prevalence rate, epidemic aspects (i.e., Cases related to gender), male to female morbidity ratio, age, and seasonal distribution.

Results: In total, there were 254 cases of EHEC with an average PR of 0.11 per 100,000 populations in Korea from 2006 to 2010. During the same period in Japan, there were 20,883 cases of EHEC with an average PR of 3.26 per 100,000 populations. The PR in Japan was significantly higher than that in Korea $(p<0.01)$. In both countries, more females than males had EHEC infections, with the highest incidence of infections (> 50\%) observed for individuals younger than 9 years. EHEC is an emerging zoonosis and may be caused by consumption of raw or undercooked meat products from ruminants.

Conclusions: This study provides a quantitative analysis of the epidemiological aspects and risk factors of EHEC infections in Korea and Japan and will provide insight on effective future strategies to reduce these infections.

Keywords: Enterohemorrhagic Escherichia coli; Outbreaks; Epidemiologic studies; Korea; Japan

\section{INTRODUCTION}

In August 1982, the Center for Disease Control and Prevention (CDC) isolated Escherichia coli serotype $\mathrm{O}_{157}: \mathrm{H}_{7}$ from the stool of four patients in two states of the United States [1]. E. coli O157 is a type of enterohemorrhagic Escherichia coli (EHEC) that produces potent toxins and causes a particularly severe disease called hemorrhagic colitis $[1,2]$. After its identification in the 1980s, EHEC was recognized as a human pathogen for the first time and has since been a common cause of foodborne illness worldwide [2]. There have been several cases of human E. coli $\mathrm{O}_{157}$ infections in Korea since it was first isolated from a patient with hemolytic uremic syndrome (HUS) in 1998 [3]. In Japan, EHEC was first reported in 1990 [4]. The main reservoir of EHEC appears to be cattle [5-12]. Therefore, contamination of food (particularly meat) or water with animal feces is likely the major source of $E$. coli O157 exposure and infections [12-21].

Both in Korea and Japan, the prevalence of EHEC in- 
fections has increased rapidly with a total of 254 cases in Korea and 20,883 cases in Japan reported between 2006 and $2010[3,4]$. Furthermore, in Korea new serogroups of E. coli (e.g., O26, O91, O103, O104, O111, O118, O121, O128, O145, and other untypable) were observed to cause hemorrhagic colitis and HUS $[3,6]$. In Japan, similar new serogroups causing EHEC infections were also observed (e.g., O26, O145, O111, O103, O121, O91, and other untypable) $[4,9]$. EHEC infections and outbreaks in humans are attributed to the consumption of undercooked meat products including beef, poultry, and pork [3-8,14,17-21]. Understanding the epidemiological aspects and major risk factors of EHEC outbreaks in Korea and Japan provides data necessary for performing risk assessment and establishing effective food safety policies.

\section{METHODS}

We investigated the epidemiological aspects of EHEC infection cases between Korea and Japan from 2006 to 2010. The following factors were analyzed: national prevalence rate $(\mathrm{PR})$, regional prevalence rate, epidemic aspects (i.e., cases related to gender), male to female morbidity ratio (MFMR), age, and seasonal distribution. In total, data for 254 cases of EHEC infections in Korea were obtained from the National Notified Disease Surveillance System at the Korean Center for Disease Control and Prevention (KCDC), Ministry of Health and Welfare in the Republic of Korea, between 2006 and 2010 [3]. Data for 20,883 cases of EHEC infections in Japan between 2006 and 2010 were obtained from the surveillance of EHEC by the Statistical System of Notifiable Disease Surveillance System at the National Institute of Infectious Disease (NIID) in Japan [4].

To quantify the impact of EHEC infections on health in Korea and Japan, we compiled and analyzed information including prevalence and relative risk factors of EHEC outbreaks during 2006 to 2010. PRs of EHEC cases per 100,000 populations in Korea and Japan, estimated using the criteria established by the World Health Organization, were statistically analyzed using one-way analysis of variance. The upper and lower limits of the 95\% confidence intervals (CIs) were calculated. Statistically significant differences between the epidemiological aspects and risk factors were determined using the chi-square test or paired $t$ test. All data analyses were performed in Excel 2007 (Microsoft Co., Redmond, WA, USA). Results were considered statistically significant for $p$ values less than 0.05 .

\section{RESULTS}

As shown in Table 1, comparative observation of the PR of EHEC (average national and regional PRs) cases in Korea and Japan were measured between 2006 and 2010 and compared. In Korea, we observed 254 EHEC cases with an average PR of 0.11 per 100,000 populations (95\% CI, 0.11 to 0.12) between 2006 and 2010. During the same period in Japan, 20,883 EHEC cases with an average PR of 3.26 per 100,000 populations (95\% CI, 3.22 to 3.30) were observed. In comparison, the PR in Japan was significantly higher than that observed in Korea $(p<$ o.01). Furthermore, the PR of EHEC cases in Seoul, the capital of Korea, was 0.09 per 100,000 populations, and that in its provinces was 0.12 per 100,000 populations during 2006 to 2010. In Japan, the PR of EHEC cases in the capital city (Tokyo) was 2.75 per 100,000 populations and in its provinces 3.32 per 100,000 populations. For both countries, we observed a statistically higher PR in the provinces compared with the capital cities $(p<0.01)$.

Table 2 lists the epidemiological aspects of EHEC cases in Korea and Japan between 2006 and 2010, analyzed by gender, age, and season. In Korea, the PR for females ( $54.3 \%$ of total cases) was significantly higher than that observed for males $(45.7 \%, p<0.05)$. In Japan, the number of females infected (53.7\%) was also significantly higher than the number of males $(46.3 \%, p<0.01)$. Additionally, we utilized the MFMR to estimate and compare the incident cases of EHEC infections between Korea and Japan. We observed similar MFMRs, of 0.89 and 0.86 , in Korea and Japan, respectively. In Korea, the rates of EHEC infection according to age group were as follows: $57.9 \%$, $6.7 \%, 2.8 \%, 6.7 \%, 6.3 \%, 7.5 \%$, and $6.7 \%$ for ages $\leq 9$, 10 to 19,20 to 29,30 to 39,40 to 49,50 to 59 and over 60 years old, respectively $(p<0.01)$. In Japan, the rates of infection in the respective age group were $36.7 \%, 14.8 \%, 15.3 \%$, $10.8 \%, 5.6 \%, 6.5 \%$, and $10.3 \%$ ( $p<0.01)$. The distribution of EHEC cases by age group were similar between Korea and Japan, with more than $50 \%$ of the cases occurring in individuals less than 9 years of age, suggesting young 
Table 1. Comparative observation of the prevalence rate of enterohemorrhagic Escherichia coli cases between Korea and Japan, 2006 to 2010

\begin{tabular}{|c|c|c|c|c|}
\hline \multirow{2}{*}{ Item } & \multicolumn{2}{|c|}{ Korea } & \multicolumn{2}{|c|}{ Japan } \\
\hline & No. (\%) & $95 \%$ CI & No. $(\%)$ & $95 \% \mathrm{CI}$ \\
\hline \multicolumn{5}{|l|}{ Nationwide } \\
\hline Total cases & 254 & & 20,883 & \\
\hline $\mathrm{PR} / 100,000$ & 0.11 & $0.10-0.12$ & $3.26^{\mathrm{a}}$ & $3 \cdot 22-3 \cdot 30$ \\
\hline \multicolumn{5}{|l|}{ Habitat } \\
\hline Capital city & $47(18.5)^{\mathrm{a}}$ & $13.7-18.5$ & $1,809(8.7)$ & $8.3-8.7$ \\
\hline PR/100,000 & 0.09 & $0.06-0.12$ & $2.75^{\mathrm{a}}$ & $2.71-279$ \\
\hline Provinces & $207(81.5)$ & $76.7-86.3$ & $19,074(91.3)^{\mathrm{a}}$ & $90.9-91.7$ \\
\hline PR/100,000 & 0.12 & $0.11-0.13$ & $3 \cdot 32^{\mathrm{a}}$ & $3.27-3.37$ \\
\hline Total & 254 & & 20,883 & \\
\hline
\end{tabular}

CI, confidence interval; PR, prevalence rate.

${ }^{\mathrm{a}}$ Statistical significant level was set at $p<0.01$.

individuals are at greater risk for infection.

According to the seasonal pattern of EHEC outbreaks in Korea, $13.0 \%, 56.3 \%, 20.9 \%$, and 9.8\% cases were reported in spring, summer, autumn, and winter, respectively $(p<0.01)$. In Japan the incidence of outbreaks for each season were $8.6 \%, 54.1 \%, 36.1 \%$, and $5.7 \%$, respectively $(p<0.01)$. Additionally, the distribution of EHEC infections throughout the year revealed that outbreaks in the spring ( $13.0 \%$ of total cases) and winter months (9.8\%) were much more frequent in Korea than in Japan $(p<0.01)$. In Korea, outbreaks increased drastically in May, peaked in July, and started to decrease in December (i.e., the onset of the coldest season). In Japan, however, outbreaks during the autumn months (31.6\%) were much more frequent compared with the respective outbreaks in Korea $(p<0.01)$. In Japan, EHEC cases occurred all year and increased drastically in June, peaked in August, and started to decrease by the end of November. Cases occurred predominantly during June and November $(77.2 \%$ of the total cases), the warmest periods in Korea, $(p<0.01)$.

\section{DISCUSSION}

Since the beginning of August 1988, stool isolation of E. coli serotype $\mathrm{O}_{157}: \mathrm{H}_{7}$ have been identified at the Center for Disease Control and Prevention (CDC) from specimens obtained from four patients in two stats [1]. EHEC were recognized as a human pathogen for the first time, and since has been a steady cause of foodborne illness worldwide [2]. There have been several cases of human E. coli O157 infection in Korea since it was first isolated from a patient with HUS in 1998. In Japan, EHEC was first reported in 1990 [4]. The main reservoir of EHEC appears to be cattle [5-12]. Thereafter, both in Korea and Japan, the prevalence of EHEC infections has increased rapidly with a total of 254 cases in Korea and 20,883 cases in Japan reported between 2006 and 2010 as showed Table 1 [3,4]. In Korea, there were a total 254 EHEC infection patients with average PR of 0.11 per 100,000 populations and that of 20,883 cases with 3.26 in Japan. Both in two countries, EHEC infections and outbreaks in humans are attributed to the consumption of undercooked meat products from certain ruminants including cattle and sheep [3,4]. These animals are infected asymptomatically and shed the organism in feces [1-4]. Particularly, PR of EHEC cases in Korea was significantly lower than Japan $(p<0.01)$. Remarkably, although Korea and Japan are located within close geographical proximity, one explanation for the differences in the PR of EHEC cases may be related to the foods of their cultures. For example, compared with the Japanese, Koreans enjoy spicier and saltier food. Koreans also frequently eat fermented foods such as kimchi. These preferences during food preparation may kill or affect the survival of pathogenic bacteria [22-25]. In addition, kimchi, a traditional Korean food, is a well-known lactic acid-fermented vegetable product 
Table 2. Comparative observation of epidemiological aspects of enterohemorrhagic Escherichia coli cases between Korea and Japan, 2006 to 2010

\begin{tabular}{|c|c|c|c|c|}
\hline \multirow{2}{*}{ Item } & \multicolumn{2}{|c|}{ Korea } & \multicolumn{2}{|c|}{ Japan } \\
\hline & No. (\%) & $95 \% \mathrm{CI}$ & No. (\%) & $95 \% \mathrm{CI}$ \\
\hline \multicolumn{5}{|l|}{ Sex } \\
\hline Male & $116(45 \cdot 7)$ & $39.6-51.8$ & $9,673(46.3)$ & $45.6-47.0$ \\
\hline Female & $138(54 \cdot 3)$ & $54.2-60.4$ & $11,210(53.7)$ & $53.0-54.4$ \\
\hline Total & 254 & & 20,883 & \\
\hline$p$ value & $<0.05$ & & $<0.01$ & \\
\hline MFMR & 0.89 & & 0.86 & \\
\hline \multicolumn{5}{|l|}{ Age, yr } \\
\hline$\leq 9$ & $147(57.9)^{\mathrm{a}}$ & $51.8-64.0$ & $7,654(36.7)$ & $36.1-37.4$ \\
\hline $10-19$ & $17(6.7)$ & $3.6-9.8$ & $3,082(14.8)^{\mathrm{a}}$ & $14 \cdot 3-15 \cdot 3$ \\
\hline $20-29$ & $7(2.8)$ & $0.8-4.9$ & $3,199(15 \cdot 3)^{\mathrm{a}}$ & $14.8-15.8$ \\
\hline $30-39$ & $17(6.7)$ & $3.6-9.8$ & $2,249(10.8)^{b}$ & $10.4-11.2$ \\
\hline $40-49$ & $16(6.3)$ & $3 \cdot 3-9 \cdot 3$ & $1,177(5.6)$ & $5 \cdot 3-5 \cdot 9$ \\
\hline $50-59$ & $19(7.5)$ & $4 \cdot 3-10.7$ & $1,367(6.5)$ & $6.2-6.8$ \\
\hline$\geq 60$ & $31(6.7)$ & $3.6-9.7$ & $2,155(10.3)$ & $9.9-10.7$ \\
\hline Total & 254 & & 20,883 & \\
\hline$p$ value & $<0.01$ & & $<0.01$ & \\
\hline \multicolumn{5}{|l|}{ Seasonality } \\
\hline Spring & $33(13.0)^{b}$ & $8.9-17.1$ & $1,783(8.6)$ & $8.1-8.9$ \\
\hline Summer & $143(56.3)$ & $50.2-62.4$ & $11,254(54 \cdot 1)$ & $53 \cdot 2-54 \cdot 5$ \\
\hline Autumn & $53(20.9)$ & $15.9-25.9$ & $6,564(31.6)^{\mathrm{a}}$ & $30.8-61.5$ \\
\hline Winter & $25(9.8)^{b}$ & $6.1-13.5$ & $1,194(5 \cdot 7)$ & $5.4-6.0$ \\
\hline Total & 254 & & 20,795 & \\
\hline$p$ value & $<0.01$ & & $<0.01$ & \\
\hline
\end{tabular}

CI, confidence interval; MFMR, male to female morbidity ratio.

Statistical significant level was set at ${ }^{\mathrm{a}} \mathrm{p}<0.01$ and ${ }^{\mathrm{b}} \mathrm{p}<0.05$.

made of Chinese cabbage, radishes, and cucumbers. A typical Korean adult consumes an average of 50 to $200 \mathrm{~g}$ kimchi per day [24]. Kimchi also produces a bacteriocin that inhibits the growth of foodborne pathogens such as

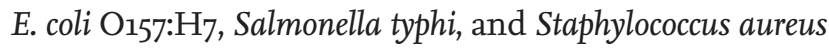
$[24,25]$.Thus, the intrinsic antimicrobial defense systems of kimchi may kill bacteria prior to human consumption [22-25]. On the other hand, in the case of the United State in 1978, epidemiological investigation of the outbreaks showed that one source of E. coli $\mathrm{O}_{157} \mathrm{H} \mathrm{H}_{7}$ is the hamburger [1]. Moreover, during the period 1992 to mid-1995, 2,946 cases of EHEC infections were reported, equivalent to annual average incidence of 0.74 per 100,000 populations [2]. On the other hand, incidence cases of EHEC infections that relate to habitat reveals that significantly more outbreaks occurred in the rural (provinces) than in other area (capital cities) in both two countries $(p<0.01)$. It is the epidemiologically believed that EHEC infection cases were reported in area where the ranching for the ruminants. Remarkably, some of the people epicures habitually consume raw or uncooked meat for an epicure were different between rural and urban areas $[2,3,6,7,14-21]$. Understanding the differences in male and female infection rates and the severity of the disease is important for public health control programs [11]. The differences observed in the distribution of infections between genders (MFMR), with more cases in females both in countries, is thought to reflect cultural differences between Korea and Japan in terms of work (i.e., women are more likely to have food-related voca- 
tions). These data strongly indicate that the incidence of EHEC cases in these two countries is influenced by their specific culture-related foods and climates [1-4,12,22,23]. The distribution of EHEC infection cases by age groups of under-9-years old, the percentage were $57.9 \%$ in Korea and that of $36.7 \%$ in Japan, respectively, and a higher PR of EHEC infections were observed in the under9-years age group more than over 20 years old group, which clearly shows a significantly higher incidence in the children, $(p<0.01)$. These data strongly indicate of communicability of EHEC that young children tend to shed the organism longer than adults. Transmission is particularly common among children still in diapers [3,11-13,18]. For example, in 1996, Japan reported 9,451 cases of EHEC infection in teenagers. Of these, 1,808 cases were hospitalized and 12 died; in addition, $75 \%$ of these cases occurred during six major outbreaks. In outbreaks reported in other areas, E. coli was isolated from salads and seafood sauces served for school lunches [2]. Furthermore, a health center in Kanazawa City reported an EHEC O111 (verotoxin 1 and 2) infection on July 7 , 2004. The patient was a high school student who had participated in a school excursion to Korea from June 28 to July 1. EHEC was isolated from 103 individuals (98 students, four teachers, and one family member) [15]. It is well-known that foodborne illnesses, including EHEC infections, are affected by season and climate changes. High temperatures and humidity can increase proliferation of and toxin production from pathogenic bacteria in undercooked meat, causing EHEC infections in those exposed [11-19].

Finally, the most effective way to prevent and control EHEC infections is to reduce human exposure to EHEC shedding in domesticated animals, particularly ruminants [1-3,1-21]. In addition, safety measures should be taken to create a comprehensive strategy against EHEC infections, including required health education and promotion for endemic areas.

In conclusion, EHEC is an emerging zoonosis and a serious concern to public health measures of prevention and control. EHEC infections are likely caused by consumption of raw or undercooked meat products from ruminants. This study provides a quantitative analysis of the epidemiological aspects and risk factors of EHEC infections in Korea and Japan and will provide insight on effective future strategies to reduce these infections.
It is our hope that this information will be a useful reference for future studies focused on EHEC infections and public health programs.

\section{KEY MESSAGE}

1. Comparing of epidemiology and major risk factors of enterohemorrhagic Escherichia coli (EHEC) outbreaks in these two countries provides information for performing risk assessment and establishing food-safety policies.

2. Prevalence rates of EHEC cases in Japan was much more outbreaks of those of Korea, because EHEC infections are likely caused by consumption of raw or undercooked meat products from ruminants.

\section{Conflict of interest}

No potential conflict of interest relevant to this article was reported.

\section{REFERENCES}

1. Centers for Disease Control and Prevention (CDC). Isolation of E. coli O157:H7from sporadic cases of hemorrhagic colitis: United States. 1982. MMWR Morb Mortal Wkly Rep 1997;46:700-704.

2. Reilly A. Prevention and control of Enterohemorrhagic Escherichia coli (EHEC) infections: memorandum from a WHO meeting. WHO Consultation on Prevention and Control of Enterohemorrhagic Escherichia coli (EHEC) Infections. Bull World Health Organ 1998; 76:245-255.

3. Korea Center for Disease Control and Prevention (KCDC). Enterohemorrhagic Escherichia coli (EHEC), and statistical system of notifiable disease surveillance system (2006-2010) [Internet]. Cheongju (KR): Korea Center for Disease Control and Prevention, c2012 [cited 2015 Sep 15]. Available from: http://www.cdc.go.kr.

4. National Institute of Infectious Disease, Japan. Enterohemorrhagic Escherichia coli (EHEC), and statistical system of notifiable disease surveillance system (2006-2010) [Internet]. Tokyo (JP): National Institute of Infectious Disease, c1998 [cited 2015 Sep 15]. Available from: http://www. nih.go.jp/niid/ja. 
5. Elder RO, Keen JE, Siragusa GR, Barkocy-Gallagher GA, Koohmaraie M, Laegreid WW. Correlation of enterohemorrhagic Escherichia coli O157 prevalence in feces, hides, and carcasses of beef cattle during processing. Proc Natl Acad Sci U S A 2000;97:2999-3003.

6. Jo MY, Kim JH, Lim JH, et al. Prevalence and characteristics of Escherichia coli O157 from major food animals in Korea. Int J Food Microbiol 2004;95:41-49.

7. Yoon JW, Hovde CJ. All blood, no stool: enterohemorrhagic Escherichia coli O157:H7 infection. J Vet Sci 2008; 9:219-231.

8. Lee GY, Jang HI, Hwang IG, Rhee MS. Prevalence and classification of pathogenic Escherichia coli isolated from fresh beef, poultry, and pork in Korea. Int J Food Microbiol 2009;134:196-200.

9. Infectious Agents Surveillance Report. Enterohemorrhagic Escherichia coli infection in Japan as of April 2012. Byogen Biseibutsu Kenshutsu Joho Geppo 2012;33:115-116.

10. Maruzumi M, Morita M, Matsuoka Y, Uekawa A, Nakamura T, Fuji K. Mass food poisoning caused by beef offal contaminated by Escherichia coli O157. Jpn J Infect Dis 2005;58:397.

11. Eshima N, Tokumaru O, Hara S, et al. Age-specific sex-related differences in infections: a statistical analysis of national surveillance data in Japan. PLoS One 2012;7:e42261.

12. Michino $\mathrm{H}$, Otsuki K. Risk factors in causing outbreaks of food-borne illness originating in school lunch facilities in Japan. J Vet Med Sci 2000;62:557-560.

13. The Center for Food Security \& Public Health. Enterohemorrhagic Escherichia coli infections [Internet]. Ames (IA): Iowa State University, 2009 [cited 2015 Sep 15]. Available from: http://www.cfsoh.iaste.edu.

14. Ezawa A, Gocho F, Kawata K, Takahashi T, Kikuchi N. High prevalence of enterohemorrhagic Escherichia coli (EHEC) O157 from cattle in selected regions of Japan. J Vet Med Sci 2004; 66:585-587.

15. Kato K, Shimoura R, Nashimura K, et al. Outbreak of enterohemorrhagic Escherichia coli O111 among high school participants in excursion to Korea. Jpn J Infect Dis 2005:58:332-333.

16. Jeon BW, Jeong JM, Won GY, et al. Prevalence and characteristics of Escherichia coli $\mathrm{O}_{2} 6$ and $\mathrm{O}_{111}$ from cattle in Korea. Int J Food Microbiol 2006;110:123-126.

17. Manago S, Kishikawa K, Tokunaga H, et al. Outbreak of enterohemorrhagic Escherichia coli O157 attributed to a grilled-meat restaurant. Jpn J Infect Dis 2006;59:407-408.

18. Muto T, Matsumoto Y, Yamada M, et al. Outbreaks of enterohemorrhagic Escherichia coli O157 infections among children with animal contact at a dairy farm in Yokohama City, Japan. Jpn J Infect Dis 2008;61:161-162.

19. Nakamura H, Ogasawara J, Kita T, Hase A, Nishikawa Y. Typing of Stx2 genes of Escherichia coli O157 isolates from cattle. Jpn J Infect Dis 2008;61:251-252.

20. Kanazawa Y, Ishikawa T, Shimizu K, Inaba S. Enterohemorrhagic Escherichia coli outbreaks in nursery and primary schools. Jpn J Infect Dis 2007;60:326-327.

21. Tsumagari K, Yamamoto H, Suganuma N, et al. Epidemiological studies of coincidental outbreaks of enterohemorrhagic Escherichia coli O157: $\mathrm{H}_{7}$ infection and infectious gastroenteritis in Niimi City. Acta Med Okayama 2000;54:265-273.

22. Lee WC, Lee MJ, Kim JS, Park SY. Foodborne illness outbreaks in Korea and Japan studied retrospectively. J Food Prot 2001;64:899-902.

23. Lee SH, Chung BH, Lee WC. Retrospective analysis of epidemiological aspects of Vibrio vulnificus infections in Korea in 2001-2010. Jpn J Infect Dis 2013;66:331-333.

24. Yoon JH, Kang SS, Mheen TI, et al. Lactobacillus kimchii sp. nov., a new species from kimchi. Int J SystEvolMicrobiol 2000;50 Pt 5:1789-1795.

25. Chang JY, Chang HC. Growth inhibition of foodborne pathogens by kimchi prepared with bacteriocin-producing starter culture. J Food Sci 2011;76:M72-M78. 